\title{
85279 - HÁBITO DE PRATICAR DANÇAS TRADICIONAIS DO RIO GRANDE DO SUL COMO POSSÍVEL FATOR DE PROTEÇÃO PARA A MOBILIDADE, EXPERIÊNCIA DE QUEDAS E QUALIDADE DE VIDA EM IDOSOS
}

\author{
Apresentação Oral - Gerontologia
}

\author{
Aniuska Schiavo / Schiavo, A / PUCRS; Cléia Rocha de Oliveira / Oliveira, CR / PUCRS; \\ Anelise Ineu Figueiredo / Figueiredo, AI / PUCRS; Lucas Athaydes Martins / Martins, LA / PUCRS; \\ Marcos Antõnio Silveira da Costa / Costa, MAS / PUCRS; Régis Gemerasca Mestriner / Mestriner, RG / PUCRS
}

Introdução: A dança folclórica do Rio Grande do Sul (RS) é uma atividade coletiva apreciada e praticada por idosos, empregando estímulos sensório-motores e cognitivos em um cenário sociocultural significativo para os seus praticantes. Objetivo: $O$ estudo avaliou se o hábito de praticar danças tradicionais do RS constitui-se como um fator protetor para a mobilidade funcional, ocorrência de quedas e qualidade de vida em indivíduos idosos moradores da região noroeste do estado do RS. Método: Estudo caso-controle, com 54 indivíduos de idade $\geq 60$ anos, divididos em dois grupos, praticantes habituais (caso) e não-praticantes (controle) da dança regionalista do RS da cidade de São Luiz Gonzaga. Os participantes foram avaliados por meio do Mini-Exame do Estado Mental (MEEM), do teste Timed Up and Go em dupla tarefa motora (TUG-DT), pela escala de Equilíbrio de Tinetti, pelo teste do alcance funcional e pela aplicação do questionário de avaliação da qualidade de vida, WHOQOL abreviado. Todos os indivíduos assinaram o TCLE. O estudo foi aprovado pelo Comitê de Ética em Pesquisa da PUCRS (2.278.677). Resultados: Os sujeitos que praticam dança regionalista do Rio Grande do Sul diferiram significativamente dos que não a praticam, evidenciando melhor mobilidade, autopercepção de qualidade de vida e a menor experiência de quedas. A análise de regressão logística binária revelou efeitos em relação à previsibilidade destas variáveis de mobilidade, equilíbrio e quedas para determinar o hábito de dançar: a) Especificamente a cada ml de água derramada no teste do TUG-DT existiu uma chance 6\% menor do sujeito pertencer ao grupo praticante de dança; b) Além disso, o fato de o sujeito não ter experienciado quedas elevou em 3,78 vezes as chances deste pertencer ao grupo praticante das danças tradicionais gaúchas, embora o achado apresente uma significância limítrofe. Por fim, verificou-se uma associação independente entre obter escores mais elevados no MEEM e na autopercepção de qualidade de vida com o hábito de dançar, bem como uma redução na quantidade de medicamentos de uso contínuo neste grupo. Conclusões: Pode-se concluir que o hábito da prática de danças tradicionais do RS provavelmente confere benefícios independentes quanto a mobilidade funcional dos idosos e contribui para uma melhor qualidade de vida e, outrossim, a dança talvez, reduza as chances de que seus praticantes experienciem quedas da própria altura.

Palavras-chave: Acidentes por Quedas. Qualidade de vida. Dança. 